\title{
Nature-Deficit Disorder
}

«Ma Ritaline à moi, c'était la forêt» déclarait le journaliste et écologiste américain Richard Louv dans son best-seller «Last Child in the Woods» (2005) [1]. Il crée le terme «Nature-Deficit Disorder» (déficit de contact avec la nature) pour désigner un syndrome avec troubles de l'attention, hyperactivité, prédisposition à la violence, surpoids et autres perturbations psychiques comme la dépression des enfants et des adolescents. Beaucoup de chercheurs confirment les conséquences du contact avec la nature sur le bienêtre intellectuel, spirituel et physique. Les jardins d'enfants en forêt, camps nature pour les enfants difficiles, trekkings pour toxicomanes, réseaux Cabanes dans les arbres ou Ecole et Nature se réclament de ses recettes contre un mode de vie dénaturé. Jouer avec des matériaux non structurés favorise imagination et curiosité, grimper dans les arbres déstresse et le spectacle des aquariums diminue la tension artérielle. La perte des expériences originelles, comme les perceptions tactiles, entraîne un autisme culturel. R. Louv prône une nouvelle éducation à l'environnement: «A quoi bon connaître la forêt tropicale si on ne connaît même pas la forêt en face de chez soi?» Les Etats industriels occidentaux ont entre-temps apporté de nombreuses améliorations à proximité des habitations: remise en état des ruisseaux, toits végétaux, apiculture urbaine et espaces verts en ville pour les enfants et les familles.

Aujourd'hui, plus de la moitié de la population mondiale vit dans des agglomérations de millions d'habitants à croissance fulgurante, beaucoup habitent dans des immeubles, travaillent à la lumière artificielle en journée et se détendent dans des univers de jeux virtuels. Le zoologiste Konrad Lorenz parle de «Verhausschweinung des Menschen», évoquant la dégénérescence des humains vers une existence proche de celle des cochons. La domestication extrême dans les déserts bétonnés des grandes villes ne réussit pas aux hommes. «Un monde sans animaux serait incroyablement dangereux», ajoute Elias Canetti. Pau-

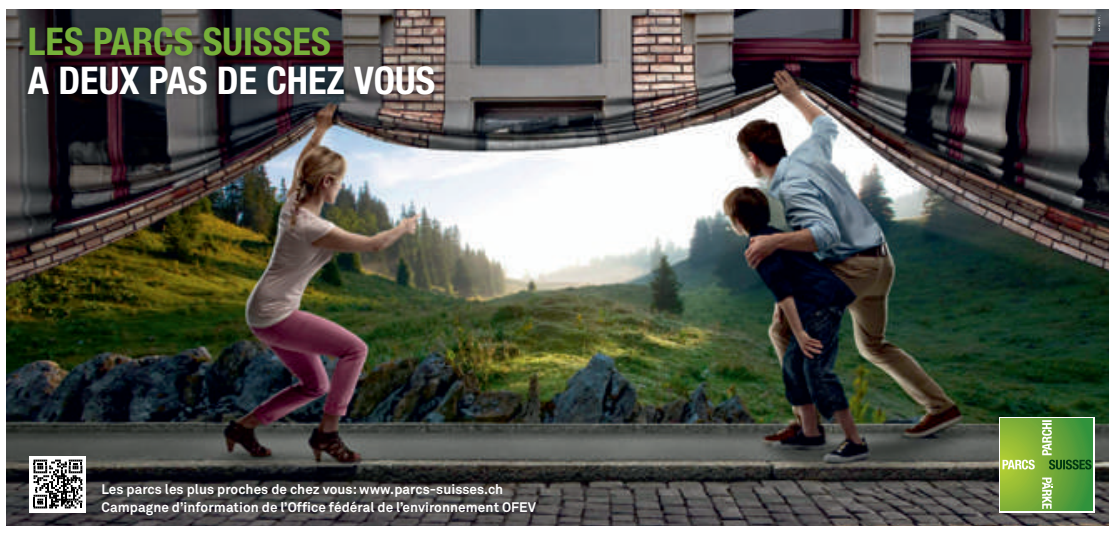

vreté et carence affective favorisent violence et folie, comme la mobilité et la déstructuration de la nature par l'urbanisation. En 1914, le Parlement suisse a décidé de faire de la Basse-Engadine un sanctuaire national, sorte de Rütli pour la nature. La campagne fédérale «Les parcs suisses. A deux pas de chez vous» (www. parcs-suisses.ch) vante la nature avec des affiches de parcs, dévoilés par une mère en talons hauts et leggins, qui soulève un rideau représentant la grisaille urbaine. Cette mise en scène pour la promotion du tourisme dans les régions rurales est valorisée et financée à l'aune de critères écologiques. Quatorze parcs régionaux suisses d'envergure nationale sont une aubaine, mais ne doivent pas servir de camouflage. Quartiers adaptés aux enfants, espaces publics dans lesquels circuler, chemins sécurisés vers l'école, nouveaux concepts d'habitation et gestion économe des ressources terrestres, endiguement efficace du flux automobile et justice sociale sont tous aussi importants.

Les trois concepts nature, environnement et milieu doivent être utilisés objectivement. Ils désignent quelque chose vierge de toute intervention humaine, qui existe sans raison, à proximité directe et reste tout de suite accessible, sans avoir besoin d'avion, d'arsenal Transa ni d'équipement outdoor. Il nous faut un vis-àvis qui nous dépasse, ne soit pas à notre mesure et nous fasse sentir notre existence éphémère et inutile sur la planète. On peut parler de transcendance ou, plus simple, d'appartenance et d'ébahissement. R. Louv n'est pas le premier à faire cette analyse. C'est à nous, adultes, de réfléchir au monde que nous voulons laisser à nos enfants. L'engagement écologique est aussi un enjeu médical, politique et subversif, car il remet radicalement en question notre mode de vie.

Le dernier dossier de Greenpeace [2] est consacré aux nouveaux espaces naturels émergeant des ruines industrielles. Le paysage post-apocalyptique de Tchernobyl, le monde sous-marin de l'atoll de Bikini, la bande verte le long de l'ancien rideau de fer, les friches de l'industrie lourde ou les usines abandonnées de Detroit: autant de parcs involontaires dans des zones sinistrées, d'hommages à la bêtise humaine et à la cupidité. Certes, nous pouvons continuer de bricoler. Et l'avenir se fera sans nous.

Erhard Taverna

1 Louv R. Das letzte Kind im Wald. Freiburg i. Br.: Herder; 2013. (Le dernier enfant de la forêt, non traduit en français).

2 Greenpeace. Zwischen Furcht und Ehrfurcht: Die Wildnis. (Entre crainte et respect: la nature sauvage) Magazine 3/2014 (en allemand). 